\title{
The Technical Analysis on Upgrade and Coupling of Low-Quality Coal
}

\author{
Bin Zhao1,2, Qiang Yao', Shan Lu', Qinggong Wang², Junfu Lv² \\ ${ }^{1}$ Key Laboratory for Modem Metallurgy Technology of Ministry of Education, Hebei United University, \\ Tangshan, China \\ ${ }^{2}$ Key Laboratory for Thermal Science and Power Engineering of Ministry of Education, Department of Thermal \\ Engineering, Tsinghua University, Beijing, China \\ Email: zhaobin19680507@163.com
}

Received 29 August 2014; revised 20 September 2014; accepted 15 October 2014

Copyright (C) 2014 by authors and Scientific Research Publishing Inc.

This work is licensed under the Creative Commons Attribution International License (CC BY). http://creativecommons.org/licenses/by/4.0/

(c) (i) Open Access

\begin{abstract}
Experimental study was conducted with regard to upgrading low-quality coal by low temperature pyrolysis technology and fluidization classification technology, which laid the theoretical foundation for research and development of low-quality coal upgrading process. Firstly, a pyrolysis pilot experiment of long-flame coal was performed and the optimum pyrolysis conditions were found. When the final pyrolysis temperature was $450^{\circ} \mathrm{C}$ and the residence time was 10 minutes, the content of semicoke volatile dry ash-free was about $22.89 \%$ and the content of semicoke ash was about $16.1 \%$. More than $5 \%$ of the ash needs to be removed before entering the pyrolysis fluidized bed. Thus, classification tests were carried out to pick out the coal particles with the target size of $500 \mu \mathrm{m}$, using a gas-solid fluidized bed coal picker. It was found that the separating effect of coal particles was the most satisfactory when the inlet velocity at the bottom was $3.27 \mathrm{~m} / \mathrm{s}$. The percentage of particles with diameters less than $500 \mu \mathrm{m}$ was as low as $28.7 \%$ in the coarse samples. Based on the test results, a novel process of low-quality coal upgrade and coupling was proposed, which realized the sorting, grading, drying and pyrolysis of low-quality coal through the multi-stage fluidized bed integrated process.
\end{abstract}

\section{Keywords}

Low-Quality Coal, Low Temperature Pyrolysis, Fluidized Bed Particle Classification

\section{Introduction}

Coal is a main product of China's energy consumption. Under the current energy situation, to develop coal clean 
technology and to improve the utilization of coal are of great significance to alleviate the pressure of the future energy. In 2012, China's total coal reserves reached 2298.9 tons. In the recoverable coal reserves, low rank coal accounted for about $40 \%$. A plenty of coal in low rank coal has high impurity (high ash, high water and high sulfur) characteristics, which is called the low quality coal.

Li Zhen, Yu Wei, Yang Chao and Zhou Anning pointed out that the treatment of low rank coal slime is an effective way on basis analysis in the comprehensive utilization of low rank coal and coal slime [1]. Gu Xiaoyu had an experimental study on two kinds of Shenhua low rank coal of thermal modification qualitative processing researches. The results showed that the thermal modification could significantly improve the coal quality characteristic of low rank coal, eventually getting low moisture and high calorific value and improving the ignition quality of modified products [2]. The Chinese Academy of Sciences Institute of the Development Process of Coal Topping Process (BT process) which uses fast pyrolysis, rapid separation and rapid cooling realizes priority use of tar oil and gas and solid products such as carbocoal which is used to generate electricity [3]. In the 1970s, the rapid development of fluidized bed pyrolysis process for a variety of bituminous coal and lignite pyrolysis were researched by Australia's CSIRO. The reactor bed of circulating fluidized bed technology is composed by the grit with $0.3-1 \mathrm{~mm}$. The residence time is short, and the energy from the flue gases of pyrolysis by the electric heater and the liquefied petroleum gas and nitrogen gas preheated air fuel formation [4].

This paper is based on low temperature pyrolysis and fluidized bed coal particles classification tests of fluidized bed. Based on the results, the process integrated design of multi-stage fluidized bed was provided for the sorting, grading, drying and pyrolysis of low-quality coal in the integrated iron system. On one hand, this design is conducive to complementary chiasma using of the waste heat in working procedures of iron making. On the other hand, the process integration design is in favour of the comprehensive utilization of low-quality coal. Furthermore, this new technology will reduce the cost of irons effectively, thus demand pressure of higher-order coal in steel industry will slow down.

\section{Characteristics of Low Quality Coal}

The main features of low-quality coal are high impurity. High impurity content will not only reduce the quality of coal, but also increase transportation costs and processing costs. If low-quality coal is directly used, it is easy to cause environmental pollution and energy waste. Taking sintering and coking as an example, with excessive moisture content, particularly with the high internal waters content in the coal, the water will break away from the surface of coal particles in the initial stage of accelerated warming, which is easy to cause the pores in the surface of coal particles ditch and even collapse and the sinter or coke exhibit more cracks. Then the mechanical strength of the product is reduced, and energy is more consumed during the heating process. Similarly, when the coal particles conduct to the liquid phase reaction by heating it, the higher ash content will impact the liquid flow resistance and reduce the bonding effect. While the mechanical strength of sinter and coke depends mainly on the full extent of liquid-phase reaction, the higher ash content will exacerbate pollution emissions. Since sinter and coke are both to enter blast furnace for iron making, the higher sulfur content will not only increase the sulfide emissions but also lead to the phenomenon of hot crisp iron. When dissolving in liquid iron in the form of ferrous sulfide, the sulfur will be enriched in the grain boundary in the solidification process, which will form low melting point eutectic, weaken the binding force between the grains and cause brittle cracking phenomenon.. For the elimination of low-quality coal high impurity process, preliminary mention quality treatment often cannot achieve the purpose of improving quality, but also requires combing the deep technology of quality, adjusting process reasonable, and using multi-stage processing means to achieve the ultimate upgrading.

In summary, to achieve efficient use of low-quality coal, it is necessary to carry out upgrading process from the source, that is, starting from the sorting and grading, not only to the reasonable control of component content in coal, but also on the particle size classification of coal particles to adapt to the needs of deep quality on low-quality coal.

\section{Key Technology of Low-Quality Coal Upgrading}

\subsection{Low Temperature Pyrolysis}

Using long-flame coal as pyrolysis experiment of coal, coal quality analysis results are shown in Table 1. As 
Table 1. Analysis of test coal.

\begin{tabular}{cc}
\hline Analysis [\%] & Value \\
\hline Mt & 19.5 \\
Mad & 11.8 \\
Ad & 17.07 \\
Vdaf & 37.53 \\
FCdaf & 62.47 \\
Qnet,ar (MJ $\cdot \mathrm{kg}^{-1}$ ) & 18.83 \\
Cad & 56.53 \\
Had & 4.9 \\
Oad & 10.98 \\
Nad & 0.45 \\
Sad & 0.28 \\
\hline
\end{tabular}

Mt is for total moisture; Mad is for inherent moisture; Ad is for dry base ash; Vdaf is for volatile content on dry ash free basis; FCdaf is for fixed carbon content on dry ash free basis; Qnet,ar is the net calorific power of as received basis; Cad is for air-dried basis carbon; Had is for air-dried basis hydrogen; Oad is for air-dried basis oxygen; Nad is for air-dried basis nitrogen; Sad is for air-dried basis sulfur.

can be seen from Table 1, the internal waters, volatile component and ash content are high. If we direct sintering or coking, it will reduce the coke strength. Meanwhile, because of higher volatile content of coal reduces the safety of production process, it also needs pre-removal. In summary, the coal used in the pyrolysis test program should be pre-dried to remove the remaining portion of the water to $5 \%$.

The muffle furnace was used within the pyrolysis test, taking $1 \mathrm{~g} \pm 0.0001 \mathrm{~g}$ of coal (diameter $<0.2 \mathrm{~mm}$ ) placed in a crucible, then set the final pyrolysis temperature at $450^{\circ} \mathrm{C}, 500^{\circ} \mathrm{C}, 550^{\circ} \mathrm{C}$ and $600^{\circ} \mathrm{C}$, respectively, residence time for $5 \mathrm{~min}, 10 \mathrm{~min}, 30 \mathrm{~min}, 50 \mathrm{~min}, 70 \mathrm{~min}$ and $90 \mathrm{~min}$. Various conditions of semi-coke volatile content are shown in Figure 1, Figure 2 is ash content of semi-coke.

From the analysis of Figure 1, with the improvement of terminal pyrolysis temperature, the energy obtained by the broken bonds the functional group increased and the rate of initial stage of devolatilization is increasing, the precipitation amount of volatiles is proportional to the final pyrolysis temperature. When the final pyrolysis temperature of $450^{\circ} \mathrm{C}$, the residence time is $10 \mathrm{~min}$, the dry ash-free basis of semicoke volatile content is about $22.89 \%$, which can meet the injection coal blending and general transport requirements of metallurgical coke. Figure 2 shows that, with the final pyrolysis temperature increases, the corresponding increase in the ash content. In the general requirements, the coal ash content of metallurgical coking is less than $12 \%$, sintering coal generally require less than $15 \%$. When the final pyrolysis temperature is $450^{\circ} \mathrm{C}$, the residence time of $10 \mathrm{~min}$, the ash content of semicoke is about $16.1 \%$. Therefore, in the upgrading process design, it needs ash handling for coal before entering into pyrolysis fluidized bed. In summary, the optimum condition of pyrolysis fluidized bed upgrading: final pyrolysis temperature of $450^{\circ} \mathrm{C}$, the residence time of $10 \mathrm{~min}$, remove more than $5 \%$ of ash before entering the pyrolysis fluidized bed.

\subsection{Fluidized Classification}

Gas-solid fluidized bed coal washer as the main body in the test equipment to conduct coal particle classification experiment research in a certain steel company. Tests mainly conducted on the effect of fluidization velocity on classification efficiency. Through the analysis of different conditions, the content of coal particle with its size less than $500 \mu \mathrm{m}$, in the lower refined coal to further determine the best classification conditions. The particle size distribution is shown in Table 2. The concentration distribution of particle size less than $500 \mu \mathrm{m}$ is shown in Figure 3. 


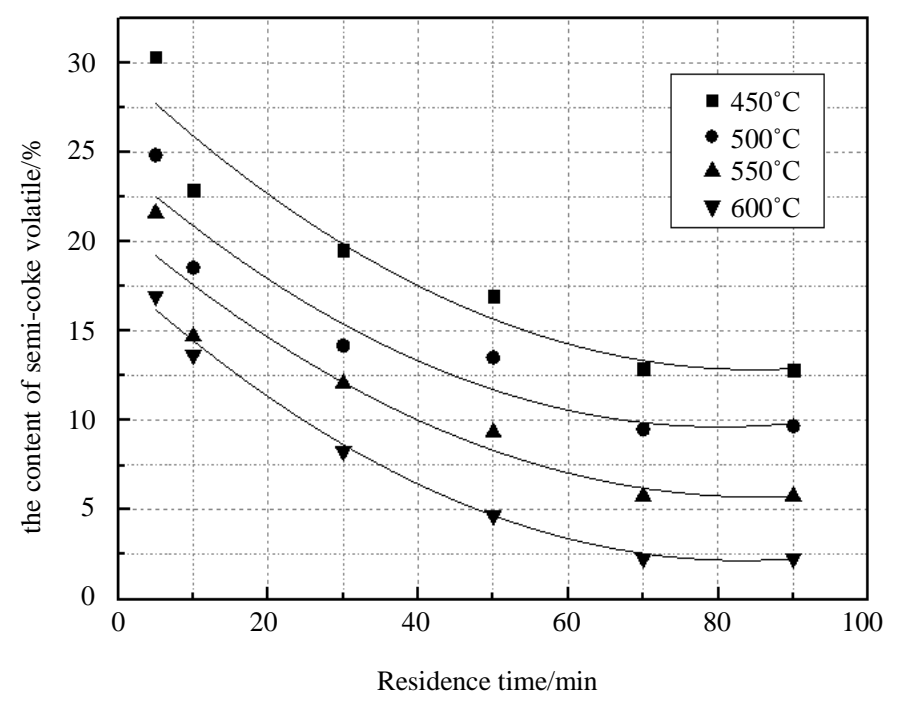

Figure 1. The content of semi-coke volatile under various conditions.

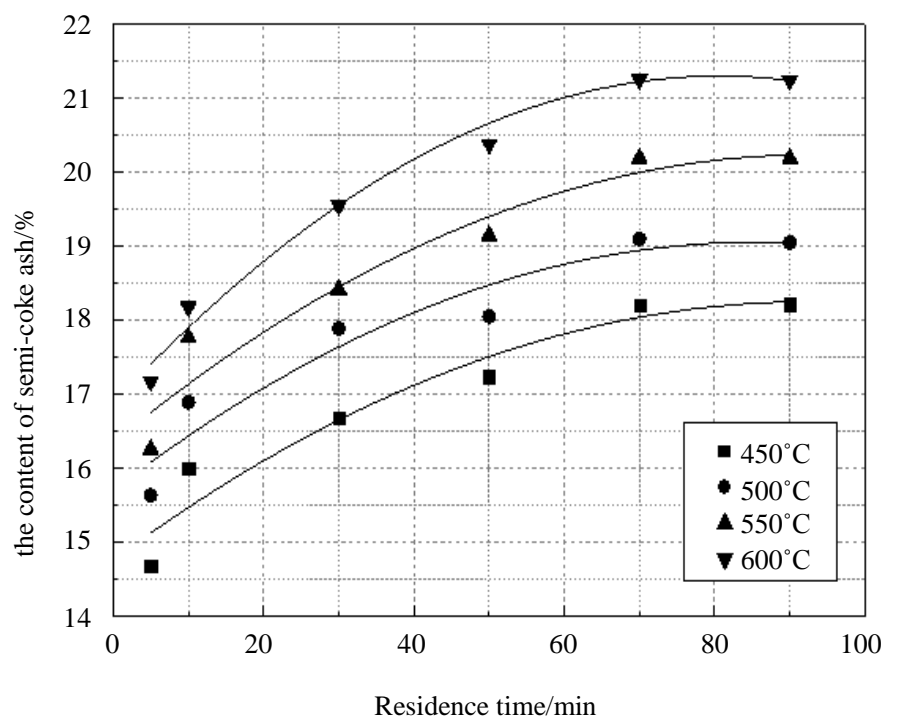

Figure 2. The content of semi-coke ash under various conditions.

Table 2. The initial parameter of coal particle size distribution in the experiments.

\begin{tabular}{cc}
\hline Particle size $[\mu \mathrm{m}]$ & Accumulative contents [\%] \\
\hline 100 & 7.57 \\
200 & 17.98 \\
500 & 60.41 \\
1000 & 72.61 \\
2000 & 90.43 \\
3000 & 100 \\
\hline
\end{tabular}




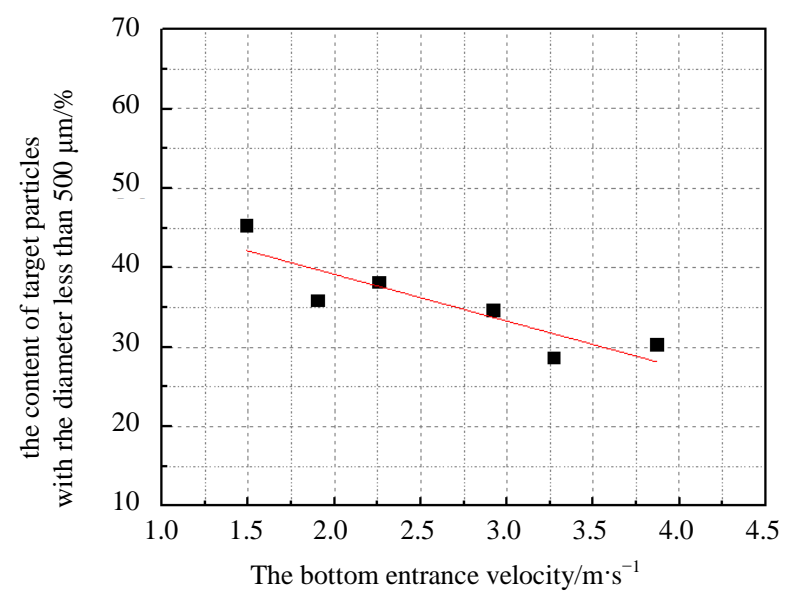

Figure 3. The content of particles with the diameter less than $500 \mu \mathrm{m}$ under different bottom entrance velocity.

It can be seen from Figure 3, with the increase of fluidization velocity, the content of coal particle with its size less than $500 \mu \mathrm{m}$ presents a descending tendency in lower refined coal. Classification has the best effect when the bottom entrance velocity is $3.27 \mathrm{~m} / \mathrm{s}$, the content of coarse coal particles the size less than $500 \mu \mathrm{m}$ reduced to $28.7 \%$.

\section{Low Quality Coal and Iron the Quality Process}

\subsection{Identified Ideas of Upgrading in Low-Quality Coal}

Accompanied by iron-making process, there have been migration and transformation of energy. And in the process of practical production, waste heat can be serious wasted, but the cause of this phenomenon is not just the quality of equipment and operational level. In order to further reduce the consumption, we should choose two points to analyze: one is the initial resource rationalization. It strictly controls the quality of materials which enter into the process system, especially the quality of coal, because coal, grain size and other factors will directly restrict the efficiencies of heat utilities. The other is rational process. On the basis of meeting the needs of normal production, the process should also take the heat recovery efficiency and continuity of coal preparation operations into account.

Our country has scarce water resources, only equivalent to $25 \%$ of the world's per capita, and regional distribution is uneven. The differences between North-South are larger. At the same time, the main coal-producing areas have less water reserves. For example, water resources of Shanxi, Gansu and Ningxia (autonomous regions) accounted for only 7.5 percent of the northern water resources and groundwater natural resources accounted for only $8.9 \%$ of the northern groundwater natural resources [5]. So, the dry coal preparation technology is more adapted to China's national conditions, not only for the promotion of industrialization, but also for the on-site processing of coal conversion.

Since the fluidization technology has large capacity and the advantages of coupling reaction and is convenient to transfer material, the coal upgrading devices are in fluidized bed as the main body, mainly including coal separation equipment and pyrolysis equipment. To further meet the coal upgrading operations, recycling different grade waste heat of sintering and coking processes will be useful for the pyrolysis of coal and dry.

\subsection{Mention Recycling Process}

Above all, a new kind of coupled low-quality coal upgrading process was presented (Figure 4). Based on the control for the low-quality coal sorting, grading, controlled drying and pyrolysis processes, the component content of the low-quality coal (such as low-grade bituminous coal and lignite) was done to achieve the sintering and coking targets. Upon completion of pulverized coal recovery, the goal of the low-quality coal replacing part of the high-quality ones was also achieved. It not only recycled the waste heat of the systems, but also improved the utilization rate of coal. 


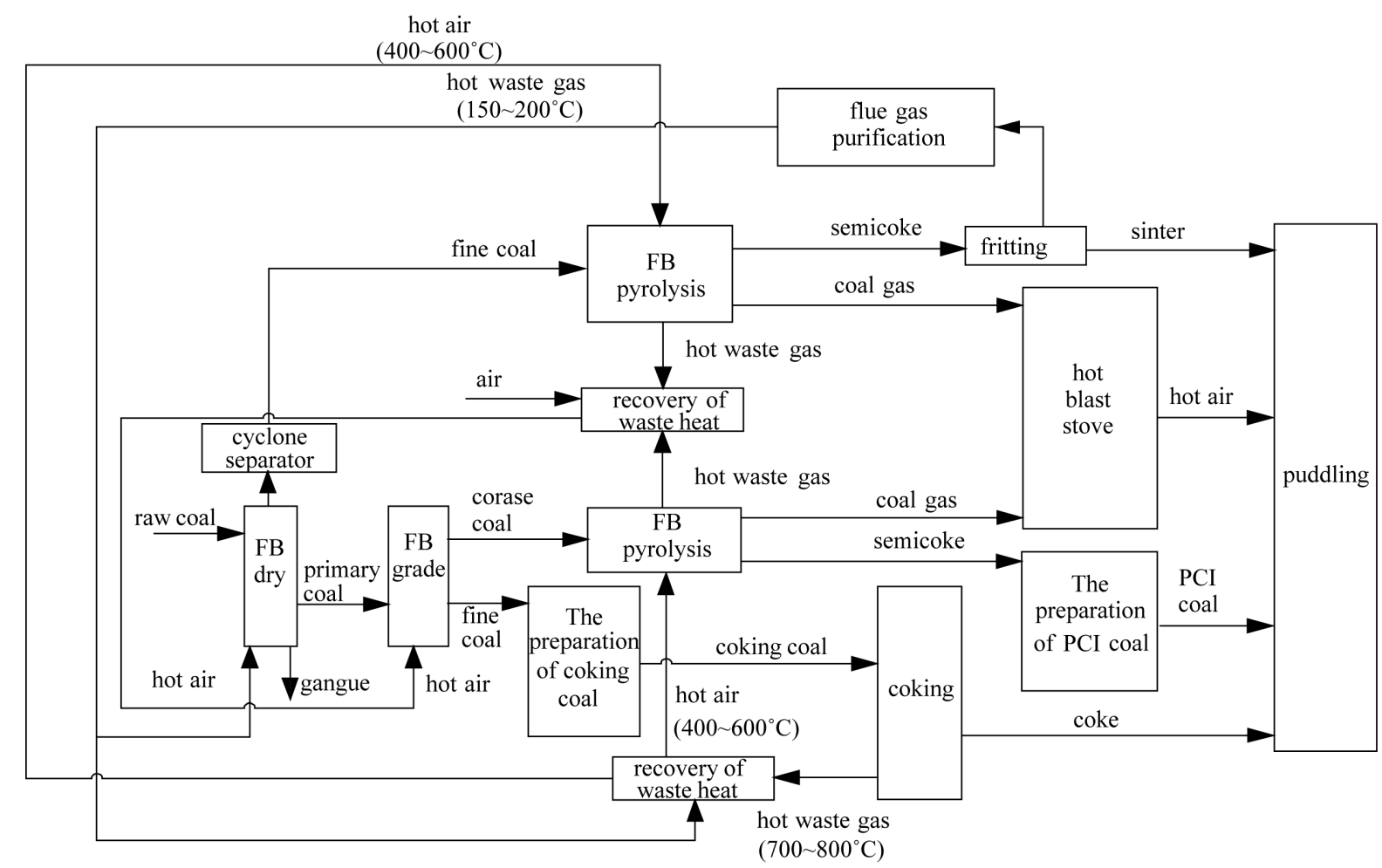

Figure 4. The system flow chart of low-quality coal upgrading.

\section{Acknowledgements}

The financial support from the National Basic Research Program of China (No. 2012CB214904) is sincerely acknowledged.

\section{References}

[1] Li, Z., Yu, W., Yang, C. and Zhou, A.N. (2013) Actuality and Expectation on Upgrading Utilization of Low-Rank Coal. Mining \& Processing Equipment, 41, 1-6.

[2] Gu, X.-Y. (2009) Study on the Upgrading Process of Low-Rank Coal by the Thermalmodification. Clean Coal Technology, 1, 89-92.

[3] Wang, J.-G. and Zhao, X.-H. (2012) Demonstration of Key Technologies for Clean and Efficient Utilization of Low-Rank Coal. Bulletin of the Chinese Academy of Sciences, 27, 382-388.

[4] Guan, J., He, D.-M. and Zhang, Q.-M. (2011) The Technology of Improving Lignite Quality through Pyrolysis and the Concept of Poly-Generation. Coal Chemical Industry, 39, 1-4.

[5] Qian, W. (2012) Experimental Study on Medium-Low Temperature Pyrolysis of Low Rank Bituminous Coal and Characterization of Pyrolysis—Derived Products. Ph.D. Thesis, China University of Mining and Technology, Beijing. 
Scientific Research Publishing (SCIRP) is one of the largest Open Access journal publishers. It is currently publishing more than 200 open access, online, peer-reviewed journals covering a wide range of academic disciplines. SCIRP serves the worldwide academic communities and contributes to the progress and application of science with its publication.

Other selected journals from SCIRP are listed as below. Submit your manuscript to us via either submit@scirp.org or Online Submission Portal.
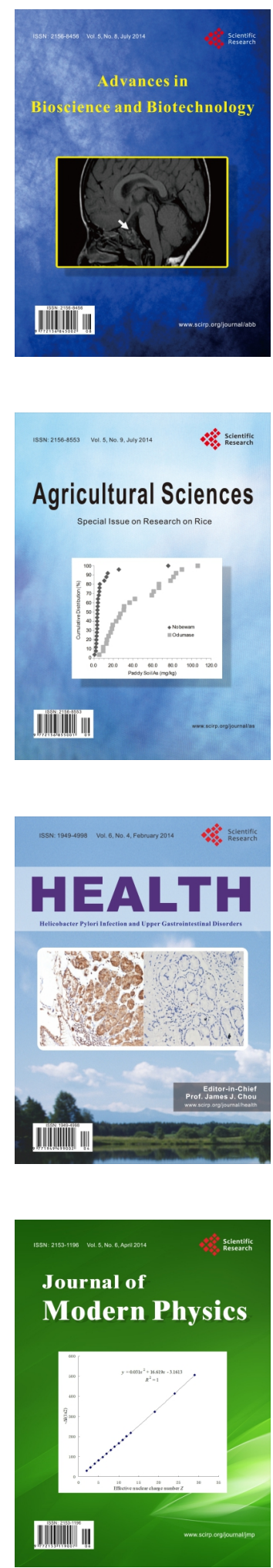
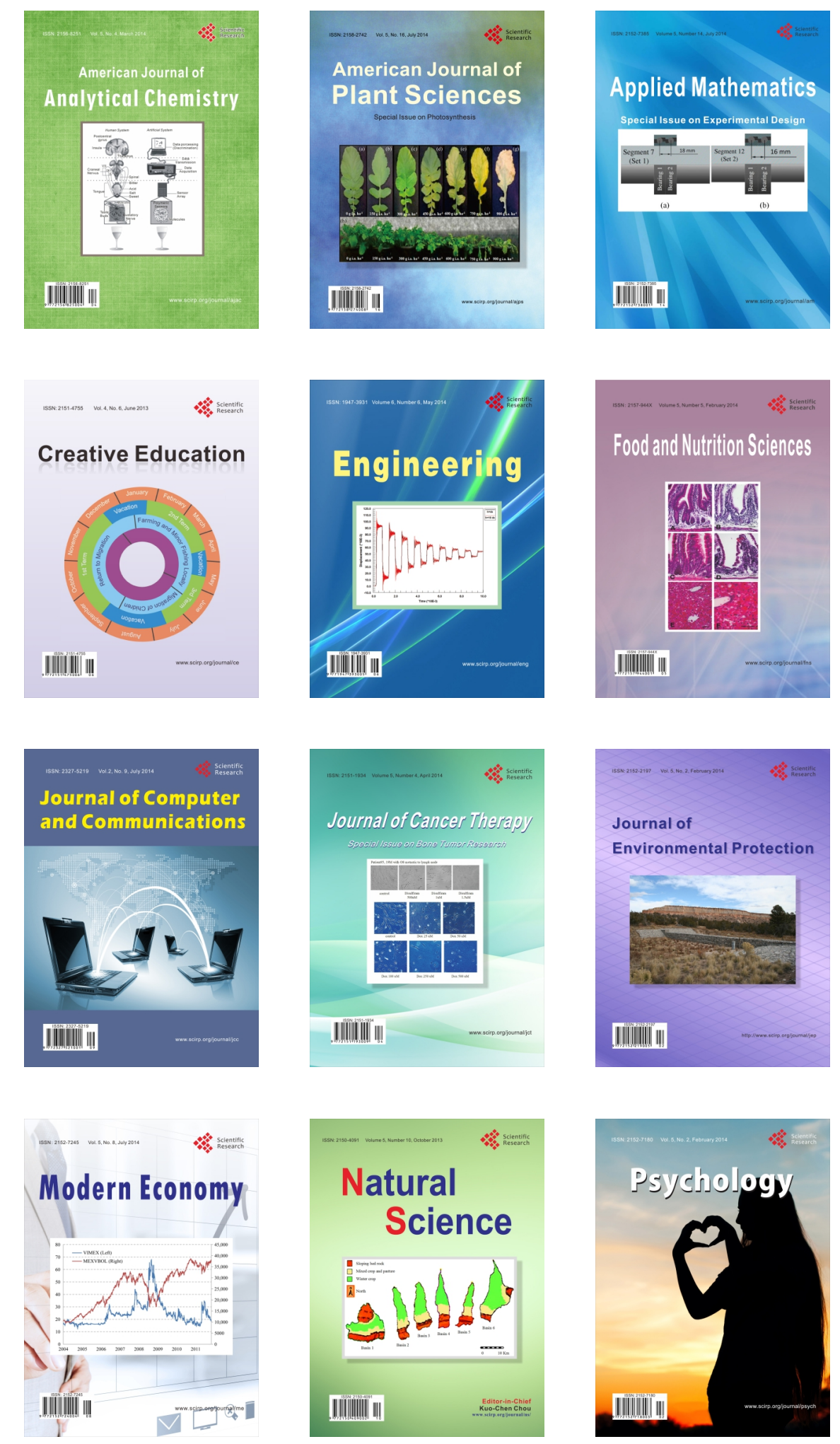